\title{
Origen, introducción, reproducción, identificación molecular y flujo genético de especies acuáticas ornamentales transgénicas en el Perú: Una revisión
}

\author{
Origin, introduction, reproduction, molecular identification and gene \\ flow of transgenic ornamental aquatic species in Peru: A review
}

Recibido: abril 26 de 2019 | Revisado: junio 18 de 2019 | Aceptado: julio 04 de 2019

\section{Carlos Scotto ${ }^{\text {I }}$ Resumen}

A nivel hidrobiológico, el territorio peruano cuenta año tras año con más especies ornamentales de diferentes colores fluorescentes por oleadas de movimientos transfronterizos a pesar de una Ley de moratoria vigente. Desde la obtención de los primeros peces ornamentales fluorescentes transgénicos a principios del siglo XXI, el número de especies hidrobiológicas se ha incrementado. Así como, la producción de nuevos "colores fluorescentes" obtenidos por la inserción de transgenes de especies de invertebrados marinos dentro de peces dulceacuícolas. A partir de su descubrimiento en el año 2006 en el Perú, se ha realizado la identificación de su fluorescencia artificial por luz UV o actínica. Asimismo, se ha efectuado la identificación a nivel molecular de los diversos transgenes que determinan el color corporal de estos peces diseñados por ingeniería genética. Hoy a casi una década de culminar la Ley de la moratoria se especula sobre su posible origen (USA y asiático) y posible flujo génico una vez que son reproducidos dentro del territorio peruano y comercializados a otros países sudamericanos. De esta manera, la presente revisión busca reunir y cruzar toda la información pertinente existente a la fecha, analizarla y dar una proyección futura de estos peces ornamentales transgénicos después del año 2021 cuando la Ley de la moratoria finalice.

Palabras clave: peces, fluorescencia, transfronterizo, flujo génico, transgén

\begin{abstract}
At the hydrobiological level, the Peruvian territory has year more year with more ornamental species of different fluorescent colors by waves of transboundary movements despite a current moratorium law. From obtaining the first transgenic fluorescent ornamental fish at the beginning of the 21st century. The number of hydrobiological species has increased year. As well as, the production of new "fluorescent colors" obtained by the insertion of transgenes of marine invertebrate species within freshwater fish. Since its discovery in 2006 in Peru. The identification of its artificial fluorescence by UV or actinic light has been carried out. Likewise, the identification at the molecular level of the various transgenes that determine the body color of these genetically engineered fish has been carried out. Today, almost a decade after the expiration of the moratorium law, there is speculation about its possible origin (USA and Asia) and possible gene flow once they are reproduced within the Peruvian territory and marketed to other South American countries. In this way, this review seeks to gather and cross all relevant information to date,

analyze it and give a future projection of these transgenic ornamental fish after the year 2021 when the Law of the moratorium ends.
\end{abstract}

1 Universidad Nacional Federico Villarreal. Lima, Perú

carlosscottoespinoza@ gmail.com
Key words: fish, fluorescence, transboundary, gene flow, transgene

(C) Los autores. Este artículo es publicado por la Revista Campus de la Facultad de Ingeniería y Arquitectura de la Universidad de San Martín de Porres. Este artículo se distribuye en los términos de la Licencia Creative Commons Atribución No-comercial - Compartir-Igual 4.0 Internacional (https://creativecommons.org/licenses/ CC-BY), que permite el uso no comercial, distribución y reproducción en cualquier medio siempre que la obra original sea debidamente citada. Para uso comercial contactar a: revistacampus@usmp.pe. 


\section{Introducción}

El 9 de diciembre del 2011, el Estado Peruano promulgó la Ley $\mathrm{N}^{\circ} 29811$, ley que establece la Moratoria al Ingreso y Producción de Organismos Vivos Modificados por un periodo de 10 años (OVM o Transgénicos) destinados a la liberación intencional al ambiente. La finalidad de esta Ley fue fortalecer las capacidades en bioseguridad, desarrollar la infraestructura requerida y generar las líneas base que permita una adecuada evaluación de las actividades de liberación al ambiente. Puesto que se percibe que se atentaría contra la biodiversidad por el potencial riesgo de flujo genético no controlado y que afectarían al Perú como "Centro de origen o de Diversidad Biológica”. Asimismo, la Ley N 27104 habla sobre la prevención de riesgos derivados del uso de la biotecnología moderna referida a los OVM con la finalidad de prevenir, evitar o reducir los posibles efectos adversos para garantizar un nivel adecuado de protección para la salud humana, la diversidad biológica y el medioambiente de los OVM y sus productos.

\section{Evolución histórica de los peces transgénicos introducidos al territorio peruano}

A principios del siglo XXI, se desarrollaron a nivel de laboratorio los primeros peces ornamentales transgénicos. La técnica para la obtención de estos OVM consistió en la introducción de genes que producen proteínas fluorescentes de colores verde (GFP,
Green Fluorescent Protein), rojo (RFP, Red Fluorescent Protein), entre otros, extraídos primero de la medusa abisal Aequorea victoria (Murbach y Shearer, 1902) y luego de la anémona de mar [(Anemonia manjano (Carlgren,1900)] y otros organismos marinos (Gong et al., 2001; Wanet al., 2002; Udvadia \& Linney, 2003). Los primeros peces transgénicos fluorescentes fueron diseñados como mascotas de acuario. Como el pez Medaka [Oryziaslatipes (Temminck y Schlegel, 1846)] (Tanaka et al., 2001; Nguyen et al., 2014) y el pez Cebra [Danio rerio (Hamilton, 1822)] (Gong et al., 2003). Cabe decir que estos peces principalmente fueron desarrollados para ser comercializados en los mercados de los Estados Unidos (http://www.glofish.com) y de países asiáticos (http://www.azoo.com.tw) respectivamente.

Actualmente, se comercializan varias especies genéticamente modificadas de peces ornamentales fluorescentes dulceacuícolas en el mundo tales como: pez Cebra [Danio rerio (Hamilton, 1822)]; el pez Monjita o Tetra [Gymnocorymbus ternetzi (Boulenger, 1895)]; el Barbo sumatrano [Puntius tetrazona (Bleeker, 1855)]; el pez Medaka japonés [Oryzias latipes (Temminck y Schlegel, 1846)]; el pez ángel o Escalar [Pterophyllum scalare (Lichtenstein, 1823)]; el Cíclido convicto [Amatitlania nigrofasciata (Günther, 1867)]; el Neón chino [Tanichthys albonubes (Lin, 1932)] entre otros (Bielikova, 2012; Panet al., 2008; Qing et al, 2012; Zhu \& Zon, 2004) (Figura 1, Tabla 1). 


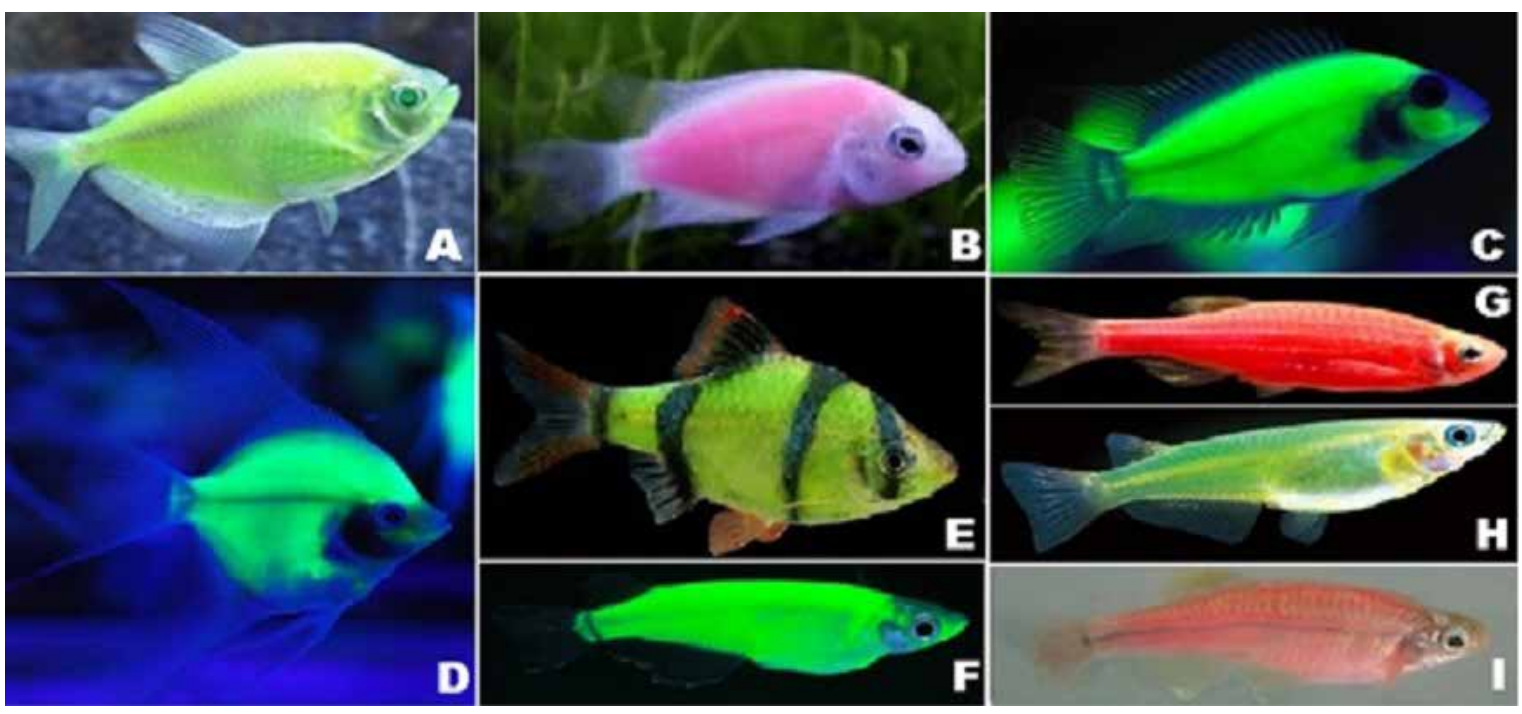

Figura 1. Peces transgénicos fluorescentes producidos: (A) Gymnocorymbus ternetzi. (B) Archocentrus nigrofasciatus. (C) Amatitlania nigrofasciata. (D) Pterophyllum scalare. (E) Puntius tetrazona. (F) Oryzias dancena. (G) Danio rerio. (H) Oryzias latipes. (I) Tanichthys albonubes (Fuente: Azoo y Glofish, 2017).

Tabla 1

Publicaciones cientificas de transgenes fluorescentes introducidos en diferentes peces (Autor, 2019).

\begin{tabular}{|c|c|c|c|c|c|}
\hline $\begin{array}{l}\text { Nombre común } \\
\text { de la especie }\end{array}$ & $\begin{array}{c}\text { Nombre científico de la } \\
\text { especie }\end{array}$ & transgen & $\begin{array}{l}\text { Efecto sobre el } \\
\text { fenotipo }\end{array}$ & $\begin{array}{l}\text { País } \\
\text { productor }\end{array}$ & $\begin{array}{c}\text { Centro de } \\
\text { origen de la } \\
\text { especie }\end{array}$ \\
\hline Pez Medaka & Oryzias latipes & GFP & $\begin{array}{c}\text { Proteína } \\
\text { Fluorescente } \\
\text { Verde }\end{array}$ & Taiwan & $\begin{array}{l}\text { Sudeste } \\
\text { asiático }\end{array}$ \\
\hline Pez Cebra & Danio rerio & GFP, RFP & $\begin{array}{c}\text { Proteína } \\
\text { Fluorescente } \\
\text { Verde y Roja }\end{array}$ & $\begin{array}{c}\text { USA, } \\
\text { Singapur, } \\
\text { Taiwan, } \\
\text { Corea del Sur }\end{array}$ & $\begin{array}{l}\text { Sudeste } \\
\text { asiático }\end{array}$ \\
\hline Pez Medaka & Oryzias latipes & GFP & $\begin{array}{l}\text { Proteína Verde } \\
\text { Fluorescente }\end{array}$ & Japón & $\begin{array}{l}\text { Sudeste } \\
\text { asiático }\end{array}$ \\
\hline Pez Monjita & Gymnocorymbus ternetzi & GFP, RFP & $\begin{array}{c}\text { Proteína } \\
\text { Fluorescente } \\
\text { Verde y Roja }\end{array}$ & $\begin{array}{l}\text { Singapur, } \\
\text { USA }\end{array}$ & $\begin{array}{c}\text { América del } \\
\text { Sur }\end{array}$ \\
\hline Pez Neón Chino & Tanichthys albonubes & RFP & $\begin{array}{c}\text { Proteína Roja } \\
\text { Fluorescente }\end{array}$ & China & Asia \\
\hline Barbo sumatrano & Puntius tetrazona & GFP, RFP & $\begin{array}{c}\text { Proteína } \\
\text { Fluorescente } \\
\text { Verde y Roja } \\
\end{array}$ & Taiwan & $\begin{array}{l}\text { Malasia, } \\
\text { Indonesia, } \\
\text { Tailandia }\end{array}$ \\
\hline Cíclido convicto & $\begin{array}{c}\text { Amatitlania nigrofasciata } \\
\text { Archocentrus } \\
\text { nigrofasciatus }\end{array}$ & GFP & $\begin{array}{l}\text { Proteína Verde } \\
\text { Fluorescente }\end{array}$ & Taiwan & $\begin{array}{c}\text { América del } \\
\text { Sur }\end{array}$ \\
\hline Pez ángel o escalar & Pterophyllum scalare & GFP, RFP & $\begin{array}{c}\text { Proteína } \\
\text { Fluorescente } \\
\text { Verde y Roja }\end{array}$ & Taiwan & $\begin{array}{c}\text { América del } \\
\text { Sur }\end{array}$ \\
\hline
\end{tabular}


Evolución histórica de los peces transgénicos introducidos al territorio peruano

En el año 2006, se identificó el primer movimiento transfronterizo de peces Cebra fluorescentes al territorio peruano (Scotto, 2011) (Figura 2).
Posteriormente, se logró su reproducción y su hibridación en cautiverio (Scotto, 2012). Y en el 2013, se logró la primera identificación de peces Cebra con la proteína roja fluorescente de la anémona de mar [(Discosomasp. (Forsskål, 1775)] en el Perú mediante el análisis de transgenes (Scotto \& Serna, 2013) (Figura 3).

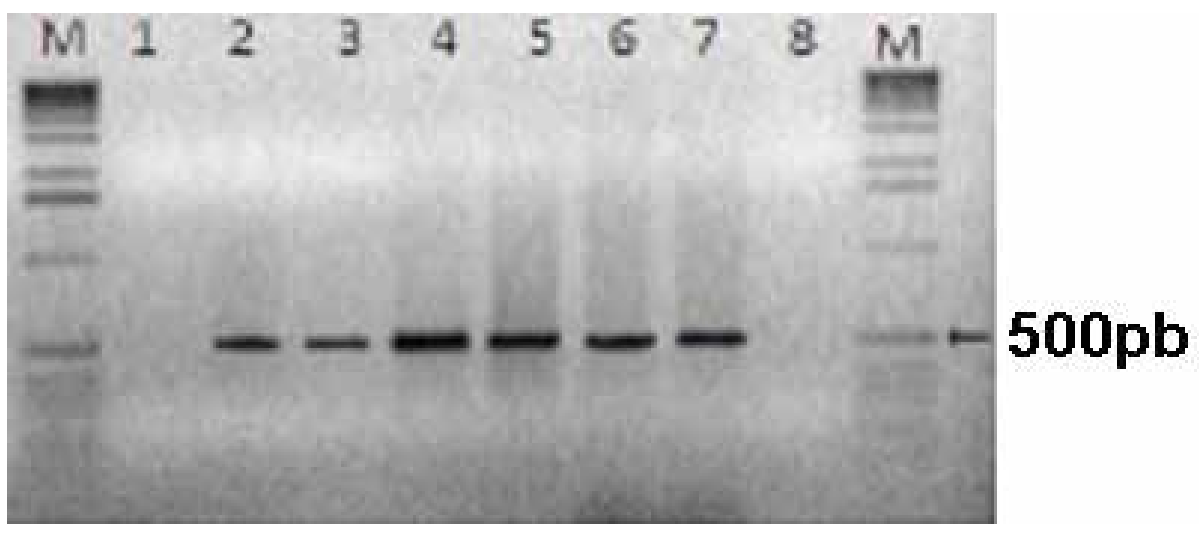

Figura 2. Corrida electroforética del amplificado del gen RFP en peces Cebra transgénicos fluorescentes. 1 = Pez de sin fluorescencia no transgénico (Control -); Carriles 2, 3 = Pez de color rosado transgénico; Carriles 4, 5 = Pez de color naranja transgénico; Carriles 6, 7 = Pez de color rojo transgénico; Carril $8=$ Sin muestra (Control -). $\mathrm{M}=$ Marcador de peso molecular de 100pb (Scotto \& Serna, 2013).

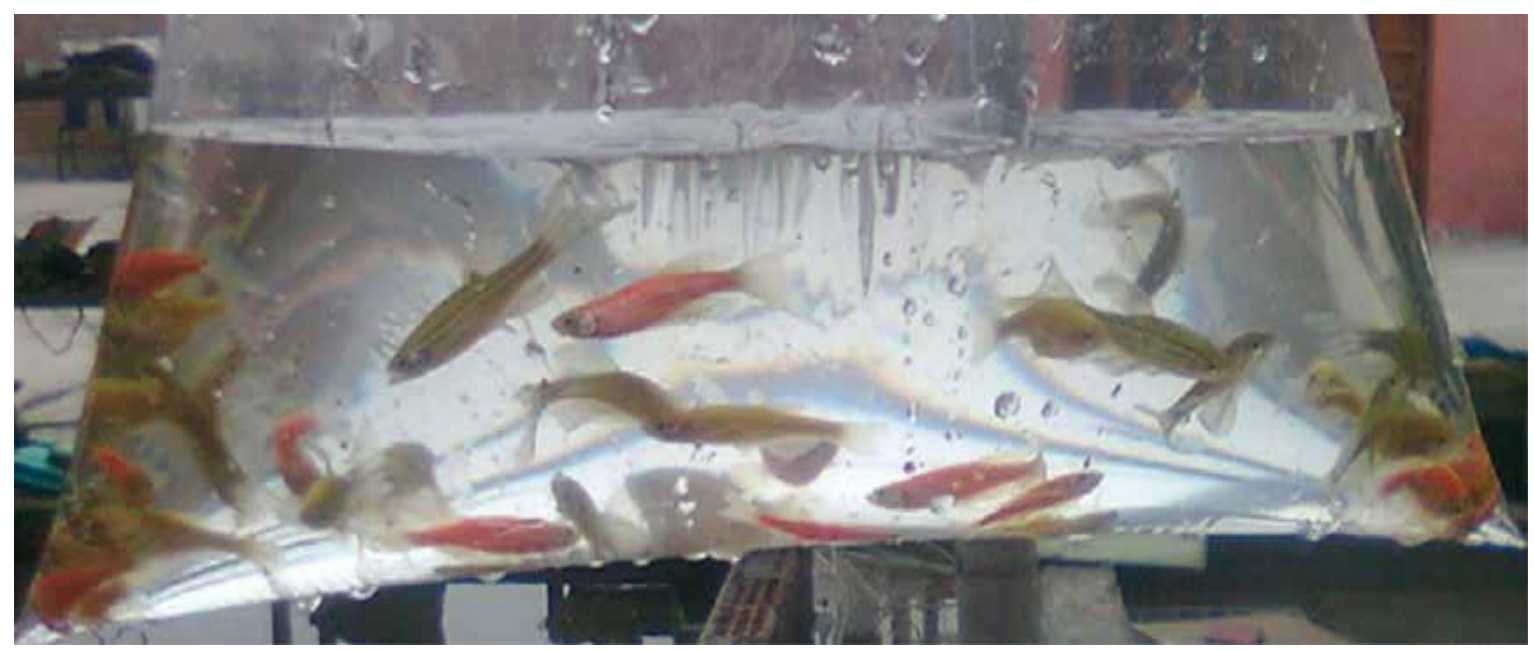

Figura 3. Acuario de la ciudad de Lima Metropolitana con peces Cebras transgénicos (El autor, 2012).

En el año 2015, se han obtenido otros peces fluorescentes transgénicos que han salido al mercado mundial como el pez Barbo (Puntius tetrazona), y en el año
2018, se obtuvo el pez Tiburón arcoíris o Labeo fluorescente (Epalzeorhynchos frenatum) (Glofish, 2018) (Figura 4). 


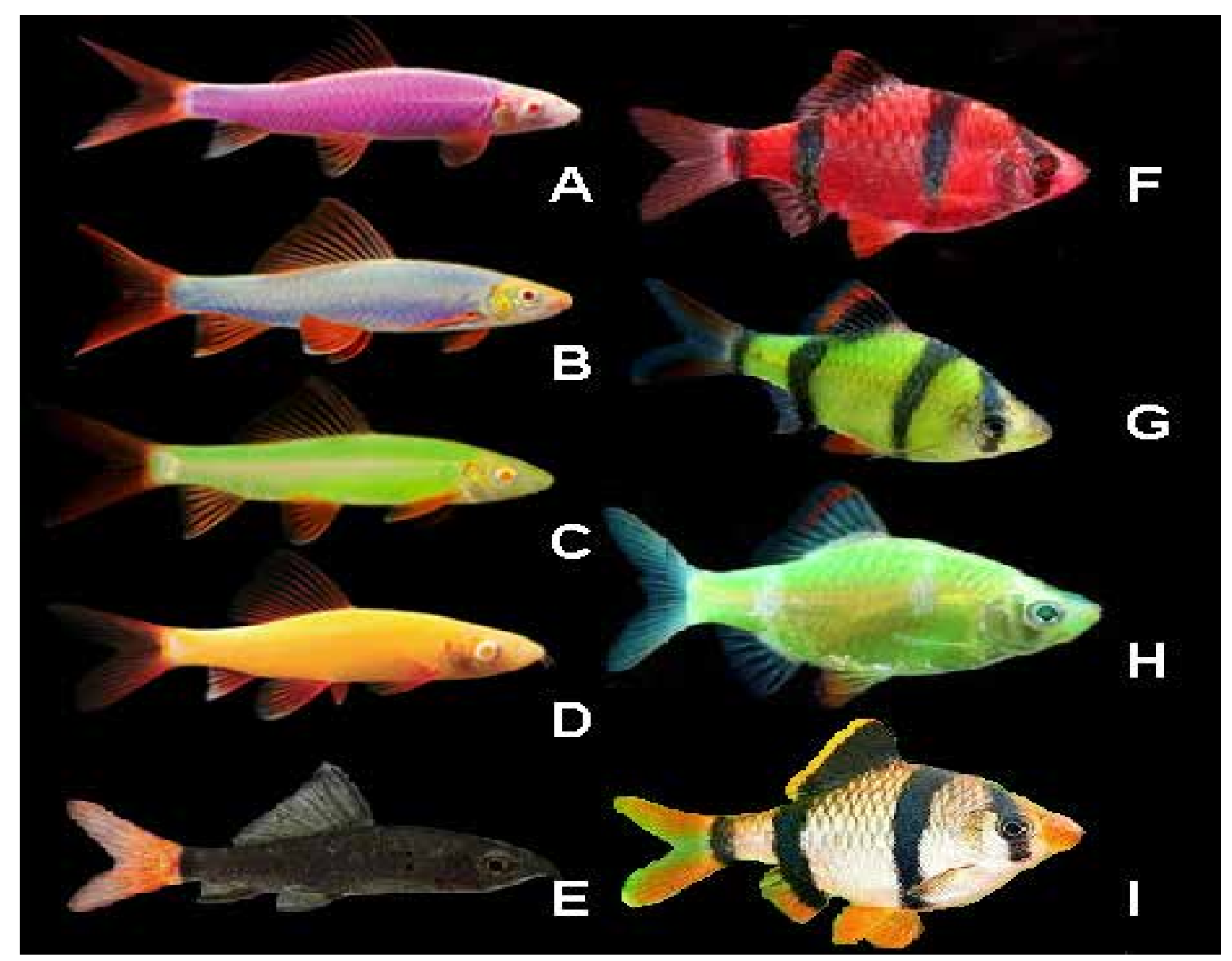

Figura 4. Peces Labeo (Epalzeorhynchosfrenatum): A. Labeo morado transgénico. B. Labeo azul transgénico. C. Labeo verde transgénico. Labeo amarillo transgénico. E. Labeo silvestre. Peces Barbo (Puntius tetrazona): F. Barbo rojo transgénico G. Barbo verde transgénico, H. Barbo albino verde transgénico,I. Barbo silvestre (Glofish, 2018).

Asimismo, en el año 2018, ya se reporta el segundo ingreso a territorio peruano de peces ornamentales Monjita o tetra transgénicos (Gymnocorymbus ternetzi) (Scotto, 2018) (Figuras 5, 6 y 9).

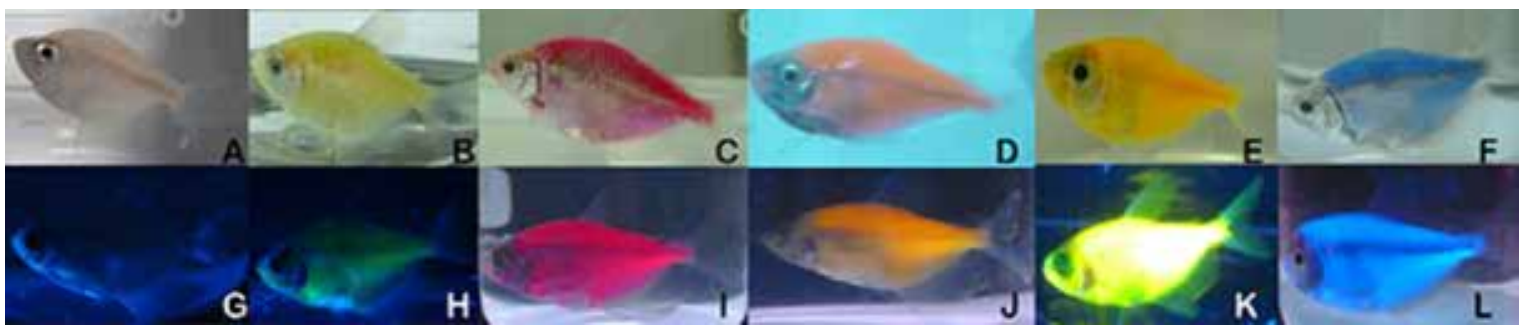

Figura 5. Con luz natural: $\mathrm{A}=$ Pez Monjita No transgénico de color blanco; $\mathrm{B}=$ Pez Monjita transgénico de color verde; $\mathrm{C}=\mathrm{Pez}$ Monjita transgénico de color morado; $\mathrm{D}=$ Pez Monjita transgénico de color naranja; $\mathrm{E}=$ Pez Monjita transgénico de color amarillo; F = Pez Monjita transgénico de color azul. Con luz UV: G = Pez Monjita No transgénico de color blanco; $\mathrm{H}=$ Pez Monjita transgénico de color verde; $\mathrm{I}=$ Pez Monjita transgénico de color morado; J = Pez Monjita transgénico de color naranja; $\mathrm{K}$ = Pez Monjita transgénico de color amarillo; $\mathrm{L}=$ Pez Monjita transgénico de color azul (Scotto, Chuan \& Pajares, 2018). 


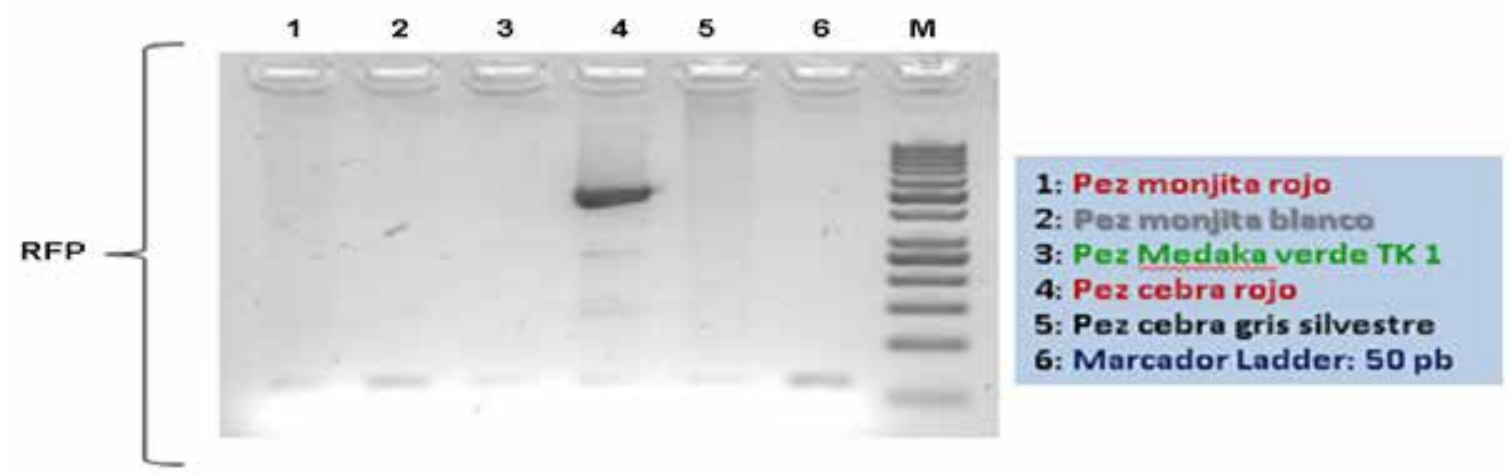

Figura 6. Electroforesis en gel de agarosa para la detección del gen de la proteína roja fluorescente (RFP) de las muestras amplificadas de: $1=$ Pez Monjita transgénico de color rojo; 2 = Pez Monjita no transgénico de color blanco; 3 = Pez Medaka transgénico de color verde; 4 = Pez Cebra transgénico de color rojo; $5=$ Pez Cebra no transgénico de color gris; 6 = Pez Monjita no transgénico de color gris; $\mathrm{M}=$ Control de amplificación de reactivos (Scotto, Chuan \& Pajares, 2018).

A partir de la segunda década del han obtenido especies dulceacuícolas segundo milenio, se ha empezado a fluorescentes como la Amatitlania producir peces fluorescentes de un nigrofasciata y el Danio rerio conocido color corporal. De esta manera, se como TK 3 (Figura 7).

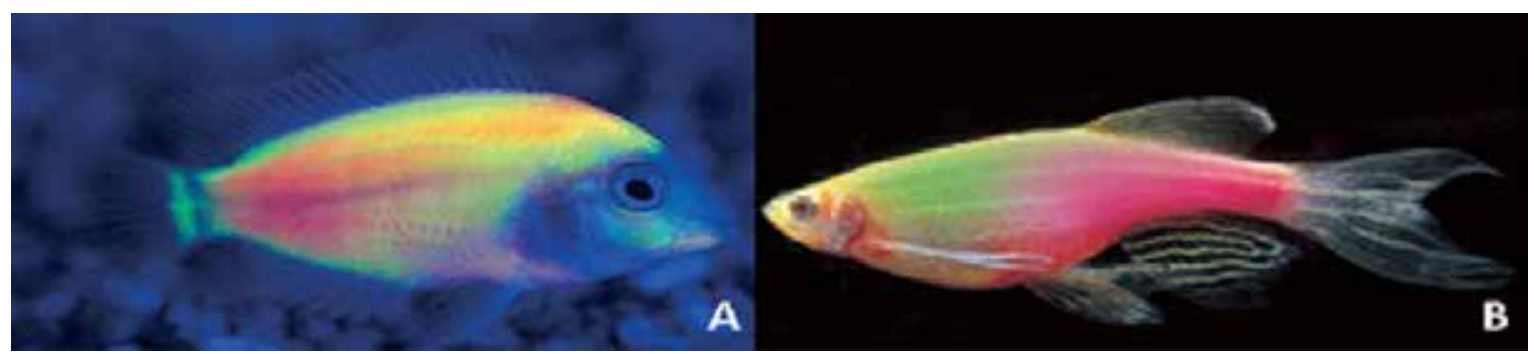

Figura 7. Peces transgénicos fluorescentes con más de un color corporal. (A) Amatitlanianigrofasciata. (B) Daniorerio(Fuente: Azoo y Glofish).

En el año 2016, se comprobó el flujo génico de los transgenes GFP y RFP de los parentales a la progenie F1 en

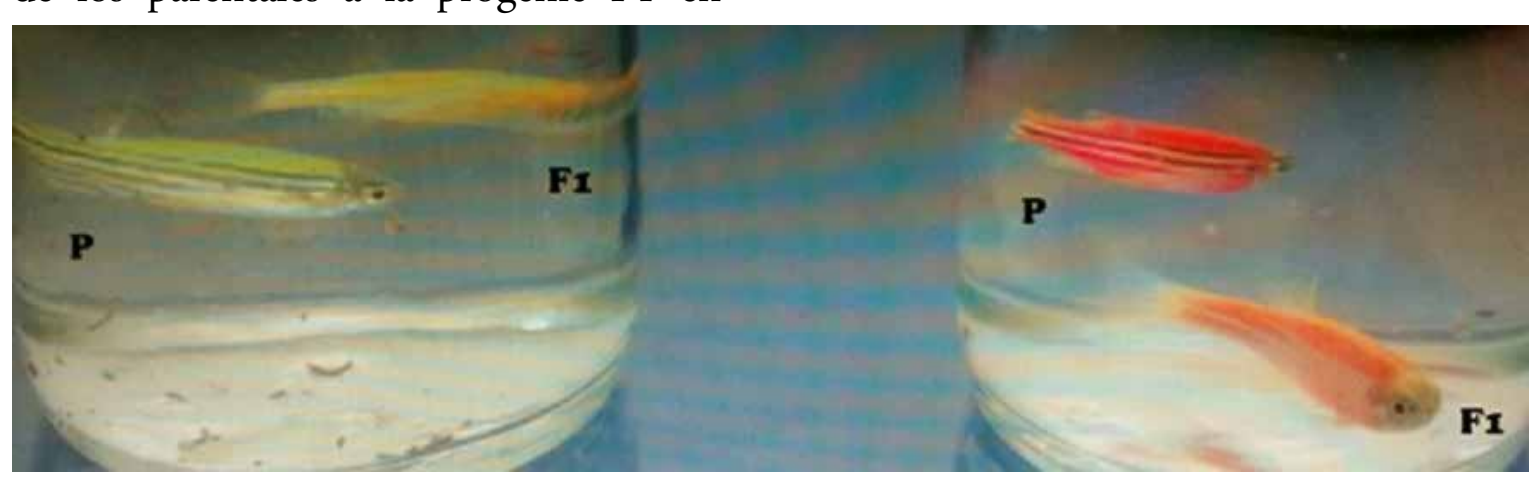

Figura 8. Identificación de la bioluminiscencia con luz natural del transgen de la proteína fluorescente verde (GFP) y de la proteína fluorescente roja (RFP) en peces Cebra transgénicos ( $\mathrm{P}$ = Parental, F1 = Cría) (Scotto \& Chuan, 2018). 
En el año 2016, se reportó la captura de peces Cebra fluorescentes de color rojo liberados en la cuenca del río Amazonas en el departamento de Loreto (MINAM, 2016). En el año 2018, también se reportóel ingreso al Perú de peces Barbo transgénicos (Puntius tetrazona) con fluorescencia roja y verde transgénico (Scotto, 2018). Probablemente, se encuentran por ingresar entre el año 2019 al 2020 los peces Labeos transgénicos (Epalzeorhyncho sfrenatum) con fluorescencia morada, azul, verde y amarilla (Figura 4).

\section{Proyección futura de los peces transgénicos ornamentales}

Actualmente, se tiene poco conocimiento del posible impacto ambiental sobre el medioambiente ante la liberación descontrolada de estos peces transgénicos por la falta de un análisis de riesgos que evalué su flujo génico (Manzi, 2016). En el Perú, existen zonas climáticas térmicamente muy semejantes a las zonas de origen de donde proceden la mayoría de estos peces exóticos (del Sudeste Asiático, de América Central y del Sur) y que podrían reproducirse y prosperar en estas zonas como son la costa norte del Perú (departamentos de Tumbes, Piura, La Libertad y Lambayeque). Además de los departamentos con zonas selváticas donde la temperatura supera los $24^{\circ} \mathrm{C}$ como son: Cajamarca, Amazonas, San Martín, Junín, Huánuco, Pasco, Cuzco, Loreto, Ucayali y Madre de Dios (Scotto, 2016) (Figura 9).

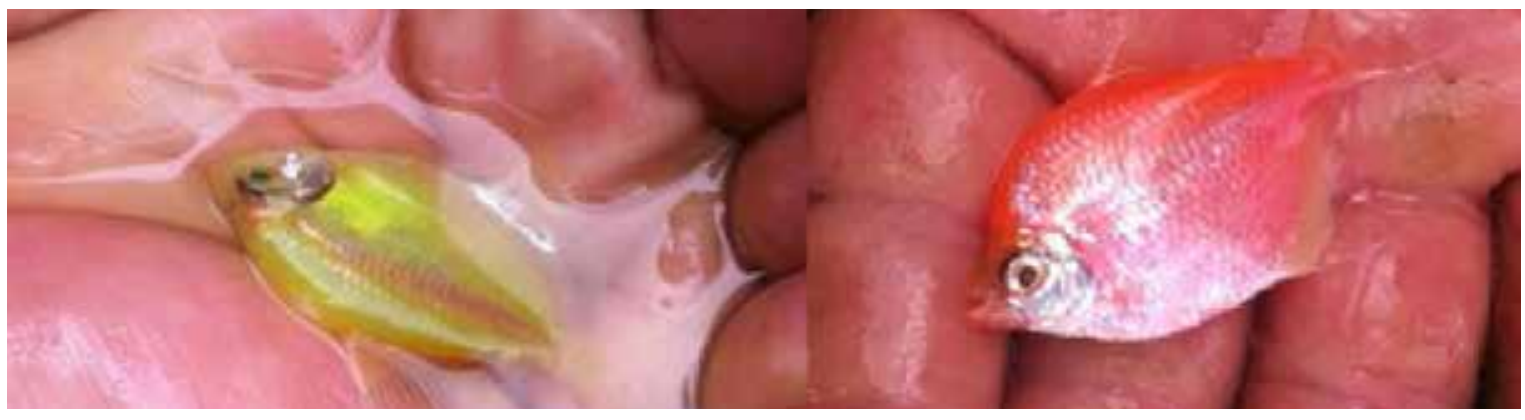

Figura 9. Peces Monjitas transgénicos verde y roja reproducidos en la selva peruana (Autor, 2018).

Por otro lado, se ha visualizado nuevos peces transgénicos de otras especies en los acuarios de Lima y ciudades de provincia

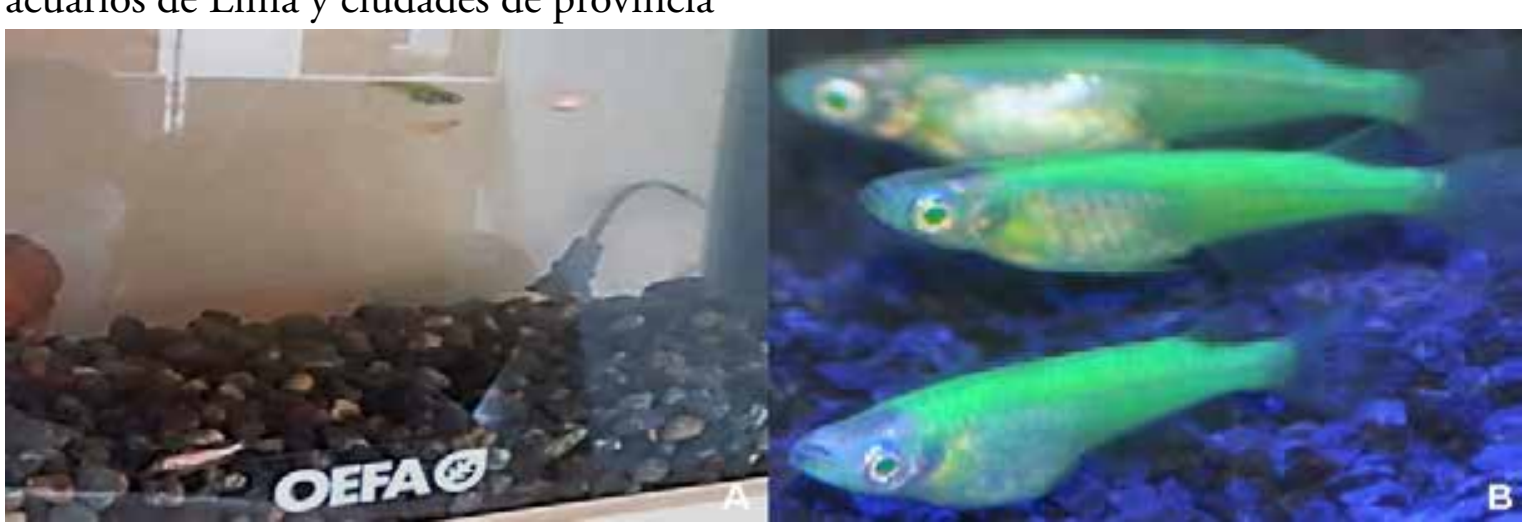

Figura 10. A. Peces Cebra y Medaka fluorescentes transgénicos en una pecera del mostrador de un organismo gubernamental peruano. B. Peces Medaka fluorescentes transgénicos en un acuario de la ciudad de Lima (El autor, 2016). 


\section{Discusión}

De los resultados mostrados (Identificación de la fluorescencia, reproducción y flujo génico de la transgenia a la progenie), se puede dilucidar que el movimiento transfronterizo de estas especies ornamentales tendría dos orígenes por ser las naciones que los reportan desde hace más de una década. Uno desde el continente asiático (Taiwán y Singapur) y otro desde USA (Glofish, 2019). Ambas rutas confluirían en países sudamericanos donde no está prohibida su comercialización e importación como es el caso de Colombia (Mercado libre, 2019; Peces cebra de Colombia, 2019).

La segunda ruta proveniente de Norteamérica partiría desde la cálida Florida donde existen muchos criaderos hacia Centroamérica (República Dominicana, Venezuela, México) (Castillo et al., 2009; Glofish, 2019) hasta confluir en Colombia y desde ahí pasar a territorio peruano llegando al norte del
Perú a los departamentos de Lambayeque y La Libertad donde han sido reportados (OEFA, 2017) y los departamentos con selva como San Martín y Loreto (MINAM, 2016). En esas zonas de altas temperaturas (Scotto, 2016) los acuaristas peruanos los reproducirían en grandes lotes de animales puros o hibridizados de peces Cebra, Monjitas y Barbos principalmente para ser distribuidos a la capital Lima y otros departamentos alejados como Arequipa, Cuzco, Puno y Tacna desde donde serían exportados a países vecinos sudamericanos como Chile, Bolivia y Argentina, lugares donde ya han sido reportados (Sernapesca de Chile, comunicación personal). Los resultados de los análisis moleculares de identificación de los transgenes para la proteína roja (RFP) y verde (Verde) de los peces Cebra encontrados en el Perú fueron idénticoos a las muestras control importadas de Asia y de Colombia evidenciándose su misma procedencia (Figuras 2 y 6). Esto permitiría especular una potencial ruta transfronteriza como se muestra en la Figura 11.

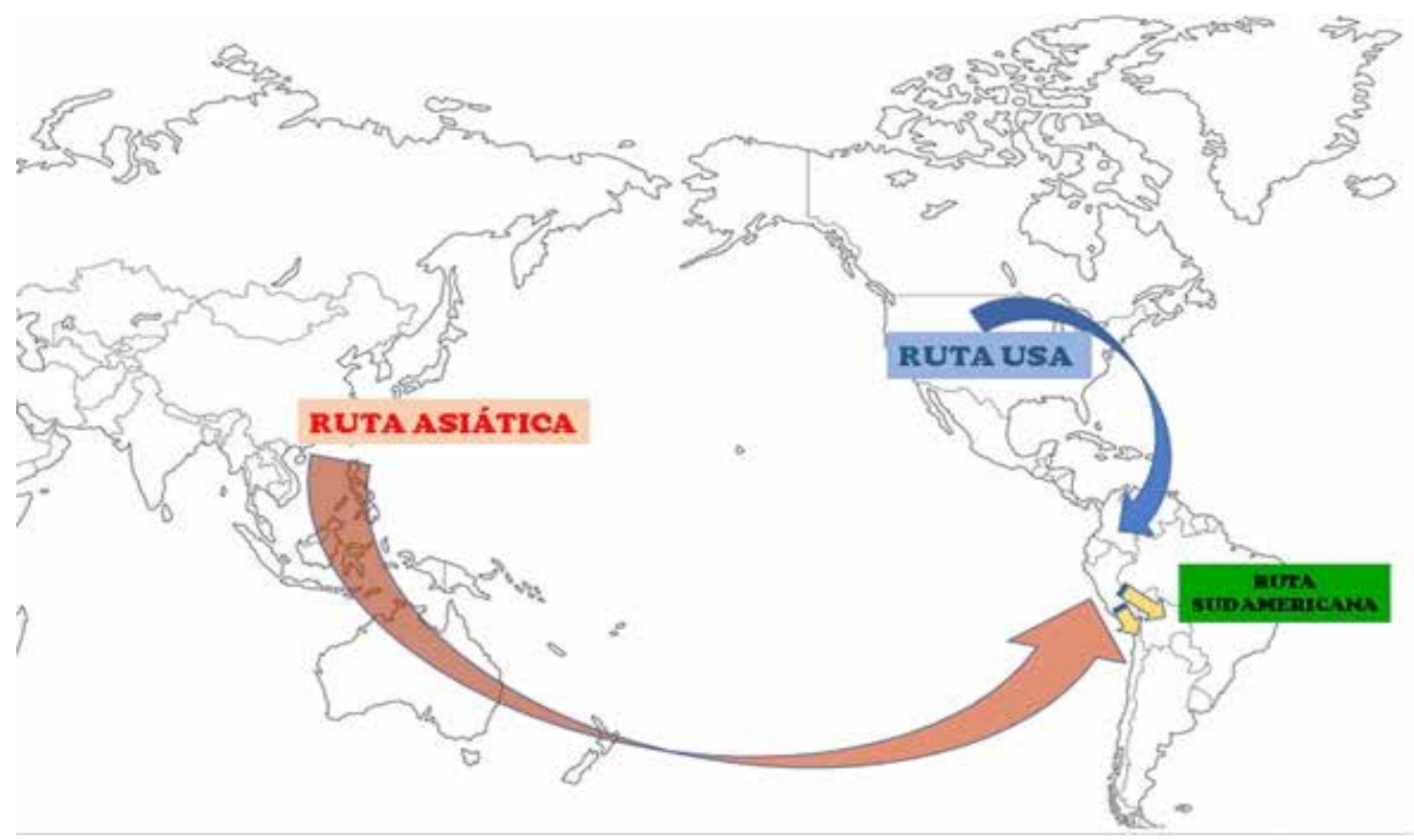

Figura 11. Movimiento transfronterizo de peces transgénicos fluorescentes hacia países sudamericanos (Colombia $\rightarrow$ Perú $\rightarrow$ Chile, Bolivia y Argentina) 


\section{Conclusiones}

La tendencia mundial es ir incrementando el número de especies ornamentales transgénicas y con nuevos colores fluorescentes. Estas especies serán cada vez más vistosas y grandes en tamaño corporal. En ellas, el color "bioluminiscente" resaltará más en un acuario. De esta manera, tendrán un mayor precio por su fluorescencia y le otorgará mayores ganancias al criador o acuarista. Todo eso ha creado un mercado muy rentable a pesar de existir leyes y normativas que buscan regularlo sin mucho éxito.

Por otro lado, las publicaciones científicas de identificación a nivel molecular de los transgenes insertos en el cuerpo de los peces transgénicos ornamentales son muy escasas o no están disponibles sus secuencias nucleotídicas en los bancos genómicos y/o el proceso de transgenia es un secreto industrial de las empresas biotecnológicas de los países que producen y venden estos organismos acuáticos por lo que la estandarización de los protocolos de identificación molecular a nivel laboratorial que faciliten un control y fiscalización aún no está del todo completamente optimizada como es el caso del pez Cebra que no permite por ahora su aplicación a otros peces fluorescentes transgénicos como es el caso del pez Monjita y del Barbo en los cuales los ensayos no han dado resultados satisfactorios por lo que urge implementarlos según la norma peruana para poder llevar un mejor control y fiscalización de estos y otros peces transgénicos que a lo largo de más de diez años han seguido el mismo derrotero para el caso del Perú.

\section{Referencias}

Azoo. 2017. En: http://www.azoo.com. tw leído el 01 de diciembre del 2018.

Bielikova, M.; Bukovska, G.; Vavrova, S.; Timko, J. \& Turna, J. 2012. Identificación de pez Cebra (Daniorerio) genéticamente modificado por métodos de PCR. En: http://gmoglobalconference. jrc.ec.europa.eu/ Posters.htm leído el 20 de noviembre de 2015 .

Castillo Alvarado, S., Sánchez, Mendoza Alfaro, R. \& Koleff, P. 2009. Los peces bioluminiscentes en México: ¿Un riesgo para el ambiente? CONABIO. Biodiversitas 85:1115.
Centro de Intercambio de Información Sobre Bioseguridad del Perú (CIISB/BCH-Perú). En: http:// pe.biosafetyclearinghouse.net/ leído el 10 de Setiembre de 2018.

GloFish, 2017. Experience the Glo! En: http://www.glofish.com leído el 01 de diciembre del 2015.

Gong, Z., Ju, B. \& Wan, H. 2001. Green fluorescent protein (GFP) transgenic fish and their applications. Genetica. Vol. 111:213-225.

Gong, Z.; Wan, H.; LengTay, T.; Wang, H.; Chen, M. \& Yan, T. 2003. Development of transgenic fish 
for ornamental and bioreactor by strong expression of fluorescent proteins in the skeletal muscle. Biochemical and Biophysical Research Communications, 308: 58-63.

Ley de Prevención de Riesgos Derivados del uso de la Biotecnología (Ley No 27104, 1999, mayo 12). Diario Oficial El Peruano, pp. 173055. En: http://www.senasa.gob.pe/ senasa/wp-content/uploads/jer/ DIR_NOR_CUAV EG/00 072. PDF leído 20 de noviembre de 2017.

Ley que establece la moratoria al ingreso y producción de organismos vivos modificados al territorio nacional por un período de 10 años (Ley No 29811, 2011, diciembre 09). Diario Oficial El Peruano, pp. 454601. En: http://minagri.gob.pe/ portal/download/pdf/marcolegal/ normaslegales/leyes/ley29811_ley_ prod_organismos_vivos.pdf leído 20 de noviembre de 2017.

Mercado Libre. 2019. En: https://listado. mercadolibre.com.co/pecesfluorescentes\#D[A:peces $\% 20$ fluorescentes]

MINAM. 2016. Servicio de consultoría para la prospección, distribución y análisis socioeconómico de peces ornamentales en las regiones de Loreto y Ucayali. Contrato N039-2016-MINAMOGA. pp 97-98. Disponible en: http://genesperu.minam.gob. pe/wp-content/uploads/2016/09/ PO 2-Prospecci \% C 3\% B 3 n distribuci\%C3\%B3n-y-analisis-
socioeconomico-de-peces-O-enLoreto-y-Ucayali.pdf

Nguyen Thanh, Vu., Young Sun, Cho., Sang Yoon, Lee., Dong Soo, Kim. \& Yoon Kwon, Nam. 2014. Cyan Fluorescent Protein Gene (CFP)-Transgenic marine medaka Oryzias dancena with potential ornamental applications. Fisheries and Aquatic Sciences, 17(4): 479486.

Pan, X., Zhan, H. \& Gong, Z. 2008. Ornamental Expression of Red Fluorescent Protein in Transgenic Founders of White Skirt Tetra (Gymnocorymbus ternetzi). Marine Biotechnology, 10:497501.

Peces cebra de Colombia. URL: https:// www.aquavidacolombia.com/ peces/-1029pez-zebra-fluorecentepara-acuarios.html

Qing, J.; Chen, M.; Bai, D.; Jiang, P.; Fan, J.; Ye, X. \& Xia, S. 2012. Generation and characterization of a stable red fluorescent transgenic Tanichthys albonubes line. African Journal of Biotechnology, 11: 7756-7765.

Scotto, Carlos. 2011. Peces transgénicos fluorescentes en el Perú: Bioseguridad y análisis de riesgos pendientes. The Biologist (Lima) 8: 235-243.

Scotto, Carlos. 2012. Nota Científica: Reproducción e hibridación de peces transgénicos fluorescentes en cautiverio: Un alcance prospectivo. Scientia Agropecuaria 3(1):89-93. 
Scotto, Carlos. \& Serna, F. 2013. Primera identificación molecular del transgén de la proteína fluorescente roja (RFP) en peces Cebra (Danio rerio) transgénicos ornamentales introducidos en el Perú. Scientia Agropecuaria 4: 257-264.

Scotto, Carlos. 2016. Nota científica: Una casuística de peces transgénicos fluorescentes (Danio rerio) liberados en ambientes naturales peruanos con condiciones térmicas similares a su centro de origen. The Biologist 14 (1): 129-141.

Scotto, C. \& Chuan, R. 2018. Cruzamiento y flujo génico de los transgenes de las proteínas fluorescentes roja (RFP) y verde (GFP) en el pez cebra transgénico (Danio rerio) introducido al Perú. Scientia Agropecuaria.Vol. 9(3): 417-421.

DOI: http://dx.doi.org/10.17268/ sci.agropecu.2018.03.13

Scotto, C., Chuan, R. \& Pajares, G. 2018. Identificación de nuevos peces ornamentales fluorescentes transgénicos introducidos al territorio peruano: a casi una década de la moratoria de OVMs. Revista Campus. Vol. 23(25):8994. DOI: doi.org/10.24265/ campus.2018.v23n25.07
Tanaka, M., Kinashita, M, Kobayashi, D. \&Nagahama, Y. 2001. Establisment of Medaka (Oryzias latipes) transgenic lines with the expression of green fluorescent eclusive in germ cells: useful model to monitor germ cells in a live vertebrate. Proceedings of the National Academy of Sciences of the United States of America, 98: 2544-2549.

Tonelli, F., Lacerdac, S., Tonellia, F., Costac, G., Renato de Françac, L. \& Resendea, R. 2017. Progress and biotechnological prospects in fish transgénesis. Biotechnology Advances 35:832-844.

Udvadia, A. \& Linney, E. 2003. Windows into development: historic, current, and future perspectives on transgenic zebrafish. Developmental Biology, 256: 1-17.

Wan, H., He, J., Ju, B., Yan, T., Lam, T.J., \& Gong, Z. 2002. Generation of Two-color Transgenic Zebrafish Using the Green and Red Fluorescent Protein Reporter Genes GFP and RFP. Marine Biotechnology, 4:146-54.

Zhu, H. \& Zon, L. 2004. Use of the DsRed fluorescent reporter in zebrafish. Methods in Cell Biology, 76:3-12. 
